\title{
FACILITATING PEDESTRIANIZATION FOR REDEVELOPMENT OF COMMERCIAL PRECINCTS, CASE STUDY AMINABAD, LUCKNOW
}

\author{
Dr. Indrani Chakraborty ${ }^{1}$ \\ Professor \& Dean ${ }^{1}$, Faculty of Architecture \& Planning Integral University Lucknow (U.P.)
}

\author{
Dr. Subhrajit Banerjee ${ }^{2}$ \\ Associate Professor ${ }^{2}$, Faculty of Architecture \& Planning A.K.T.U Lucknow (U.P.)
}

Article DOI: https://doi.org/10.36713/epra4157

\begin{abstract}
The early stages of urban development people tended to focus on solving the problem of vehicular traffic, so now a large number of existing roadways are occupied by vehicles, triggering disputes and problems about pedestrian safety and comfort. Despite its modernistic and functionalistic origins, the pedestrian street became an important theme for many writers interested in the social life, history, scale and aesthetics of the traditional European towns The territorial strategy of the pedestrian precinct is primarily about demarcating a certain territory for pedestrian use, prohibiting car traffic, and limiting cycle traffic within the area. urban growth with sprawl is completely unpleasant and unwanted and the correct solution is "intermediate cities" to integrate all of the suitable aspects in a city. As you considered, this article discusses about pedestrianization and its benefits. In a city with large growth especially in developing countries, one of the cases that usually are neglected is pedestrianisation and attendance of citizens in urban spaces.
\end{abstract}

\subsection{INTRODUCTION}

The most memorable public places in our cities and towns are generally those places where people congregate on foot - the streets, parks, and squares. These are democratic places that make our towns and cities liveable and vital. Our streets especially have a significant responsibility to be accessible to all, and to be functional, safe, and attractive places to walk. However, despite its ubiquitous nature, walking itself is not something people think or talk about very often.

However in the present day, the public space is dominated by vehicles; this ceates conflicts with pedestrians' movement, increases noise and air pollution, and increases the lack of safety for pedestrians and non-motorized transit users. Additionally, parking, shop extensions and unorganized vending add to the existing chaos. Like so many other public spaces in historic core areas of Indian Cities, Aminabad area too is experiencing a loss of human character in the area, and an overall deterioration of public life.

Safety of pedestrian is a basic step toward a safer city. Pedestrian transportation network are the nerves of a city and every persons of city is a pedestrian at some point. There is need to measure and improved pedestrian infrastructure in city for safe, convenience and comfortable walking trips of pedestrians. I think it is clear that we can begin to tackle the problems of the changing needs of our society, and to seek a way of life that can sustain future demands through the creation of facilitating pedestrianization in urban precincts. 


\subsection{Aminabad As A Public Space}

The study focused at various factors of pedestrians' crashes. The research also examined pedestrians perception of their environment and the preference they have of pedestrian facilities, and identify that can result from new or improved pedestrian facilities. Pedestrian have direct interaction with vehicular traffic that results in more number of pedestrian accident. Pedestrians are also have problem to crossing road due to increased travel time or increased in crossing distance. Walking is a basic and oldest mode of transportation. Every trip begins and ends as a pedestrian trip. A pedestrian is someone traveling by foot. People walk many reasons, to go to a market, college and school. People also walk for recreation, health purpose or for enjoy outside environment. Every people do it every day as some part of every trip but in planning, design of our communities has generally received no attention. Increasing the use of walking as a transportation choice can help reduce some of congestion on roadways.

According to the most credible version of the history the land on which Aminabad stands belonged to Rani Jai Kunwar Pandey. The Rani, besides being a vassal of the Mughals, was also a very good friend of Khadija Khanam, the Begum (wife) of the first Nawab of Oudh, Saadat Khan Burhan-ul-Mulk, who was also the Grand-Wazir of the Mughal Empire. [1]

The Rani constructed a Mosque on this land and gifted it to her good friend, the wife of the Nawab. This 18th century Mosque, known as Padain Ki Masjid (The Brahmin Woman's Mosque), still stands in Aminabad. The maqbara of Begum Khadija Khanam was also constructed in front of the masjid, but it has been lost to the vagaries of time, though the grave is still to be seen.[1]

By the time the Nawabs moved their court from Faizabad to Lucknow, the site had become a center of activity and irregular commerce like weekly market etc.. It was a part of the city known as Masarratganj. The actual land on which Aminabad later was built had passed under the possession of Sikandar Shikoh, a son of the Mughal emperor Shah Alam II. After the death of Sikandar Shikoh his wife became custodian of the property in Masarratganj and she sold it for Rs.2800/to Nawab Imdad Husain Khan Aminuddaulah, who was the Prime Minister of Nawab Amjad Ali Shah, the fourth Nawab of Lucknow. This was around 1840s.

Aminuddaulah was a visionary and he took upon the task of metamorphosing this area into a developed zone. Over the following years concrete houses, shops and parks replaced the thatched huts and ramshackle shelters in the open fields. Traders, craftsmen and entertainers were encouraged to set up their establishments. Four gates had been erected on all the four sides and each gate had an adjoining mosque. The biggest gate known as Kalaan Phatak was at the main crossing and the mosque near it was also called Kalaan Phatak Masjid. Towards the west was the smaller Khurd Gate near Mehra Cinema on Gwynne Road. The gates no longer exist but the mosques are still there and are known by their original names. Aminuddaulah also initiated the construction of a big park in the open space within the rows of the newly opened shops during this time.

After the revolt of 1857 the rule of the Nawabs came to an end and the Aminabad came under British rule. After the mutiny of 1857, the entire area came under the rule of the British. Later in $1905 \mathrm{Lt}$. Governor Sir J.D. Latouche, visited Aminabad and ordered its renovation. It was then that Loutouche Road leading to this market came into existence and till date is called so. The renovated Aminabad was inaugurated by Sir Loutouche himself in 1911.[2] 


\section{EPRA International Journal of Research and Development (IJRD)

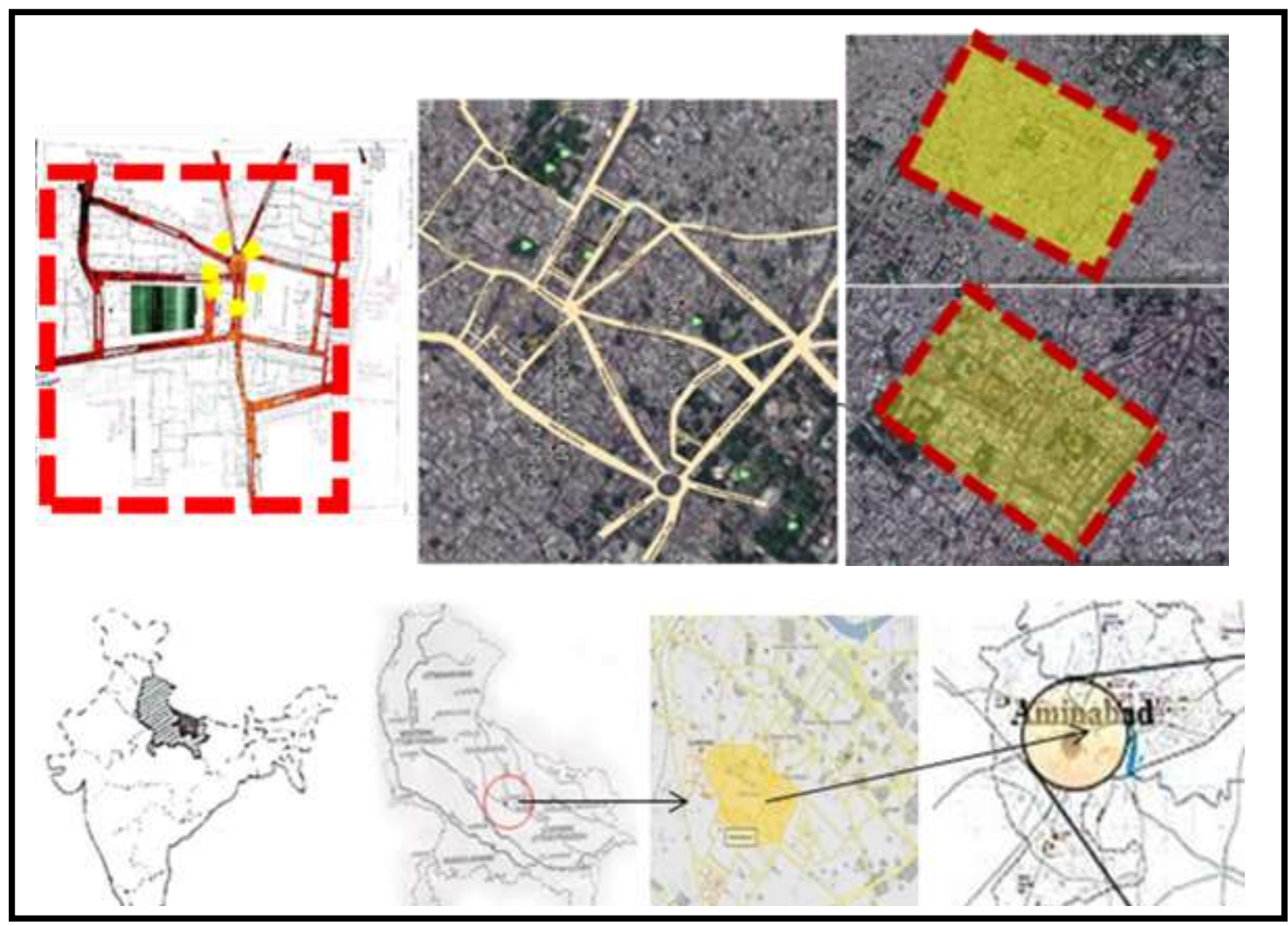

Fig 1 Site area

Meanwhile, Babu Ganga Prasad Varma came to live in Aminabad in 1910 and designed the market with big corridors so that roads could be used for walking Ganga Prasad memorial hall was built by him for public functions. He was the one who came up with Goonge Nawab Park. [3]

In 1912 the British government made a master plan for this area and, as per the plan, roads on all the four side of this park were laid out and the park came to be known as Aminuddaulah Park. In the following years the importance and stature of Chowk and Nakhas bazaar started receding and Aminabad gained ascendancy, and Aminuddaulah Park became not only the talk of the town but the nation itself. In 1928 it was at this park where during the struggle for independence the freedom fighters first hoisted the tri-colour. That eventful day was followed by the address to the nation by Mahatma Gandhi for the civil disobedience movement. Many more leaders including Jawahar Lal Nehru, Atal Bihari Bajpayee and Subhash Chandra Bose gave fiery speeches for independence at this platform. The huge congregation that had gathered at Aminuddaulah Park to listen to Jawahar Lal Nehru was brutally lathi-charged by the British force and several people, including Nehru, got hurt. Gulab Singh Lodhi had climbed up a tree in the park and hoisted the tricolour flag. The British police shot him down and later on his statue was installed in the centre of the park and still stands there. The park by now had acquired the name of Jhandewala Park because flags of various Indian political parties fluttered here. Prior to independence the literati of the city had made Aminabad their place of dwelling and they eagerly awaited the leading Indian newspapers like Humdum, Haqeeqat and Pioneer each morning. Newspaper vendors would come to the main crossing early morning and their wares were sold till late evening. The writers, poets and educationists even then frequented Danish Mahal in the ground floor of Central Hotel, and the nearby Siddiq Book Depot and Anwar Book Depot. There was a time when at these erudite centres one could have come across the likes of Syed Masood 
Hasan Rizvi, Dr. Shujaat Ali Sandilavi, Josh Malihabadi, Prof. Ehtesham Husain, Nawab Mir Jafar Ali Khan 'Asar', Majaz and many more. The owner of Danish Mahal, Nasim Ahmad, who passed away recently, was not only well-conversant with all kinds of books, but was also familiar with the persona and wherewithal of the stalwarts of the town.44]

Since the time of Nawabs, the market boasts of its unmatched fashion, and being one of the oldest markets, it is still surrounded by buildings and architectures of nawabi era.

\subsection{THE HISTORIC AREA: AMINABAD}

Aminabad is a major commercial area of Lucknow, built under the reign of Amjad Ali Shah between 1842 and 1847. It is located on the southern side of the River Gomti, to the west of the new market area of Hazratganj and south of the conservation zone. His minister Aminuddaullah conceived it as a grain and vegetable market. Long rows of shops and warehouses were built with a rose garden in the rear. In later years, however the grain market moved out to other locations and it is now the largest clothes and general merchandise shopping area for the city. It is linked to other smaller markets around it - the hardware market on Sri Ram Road, guns and bullets on Latouche Road, small knick-knacks in GarbarJhala and vegetable markets in Nazirabad and Qaiserbagh. All these together form a major destination for the people of the city. The market area is concentrated around two main parks. These parks form large open spaces around which commerce can flourish. Half the area of the main Aminabad Park was converted into small temporary shops for the refugees who moved to the city after the Partition in 1947. This has now assumed a more permanent nature. The park behind has a main temple and a clock tower, which were both major landmarks in the area once. Now the park is neglected and the shops have almost enveloped the temple having extended even into the basement area of the temple. The second and larger park is called the Aminuddaulah Park that once had the tomb of Aminuddaulah in the center. In 1997, this park was transformed into a multilevel underground parking and shopping complex commissioned as a public-private project by the city. It shall house about 500 new shop and provide parking for 100 cars. This concrete structure projects above the ground for about 5 feet and has a central glass atrium and four traditional looking staircase structures on sides to allow access. The structure is nearly complete, but construction has been stopped ah Pak' and occupation denied by a stay order from intersection the Supreme Court of India in response to a it shops public-interest litigation. The appellant has questioned the incorrect interpretation and application of landuse zoning by the city. Buildings of uniform color and style surround th this park on three sides: predominantly institutional buildings on the north side, large residences on the west side and storefronts on the south side. The area surrounding these parks and edging the streets traditionally has been commercial. Beyond this layer, however, there co-exists a traditional residential community. Its streets are irregular, curving and private serving courtyard houses. Two other smaller parks existed here, one for children or private use and the other only for women. This area though is seeing a huge expansion in commercial activities and the two activities are in conflict, Benefits of heritage tourism The promotion of heritage tourism is a win- win situation for both the inhabitants of the core city as well as the tourists who come to visit the place. The benefits of heritage tourism can be summarized as below:

- Tourists have fulfilling experiences

- Resources get needed maintenance attention by the city administration

- Hosts receive meaningful economic return

- Historic past is preserved

- Underutilized historic resources are developed

- Ways are found to make attractions out of archaeological traditional values

- Historic and cultural sites attract visitors and rehabilitation of existing buildings is often cheaper than building a new structure

- Out migration of the original residents of the core city areas is stopped

- Promotion of heritage tourism can help in conserving the tangible and intangible heritage of the core city areas 


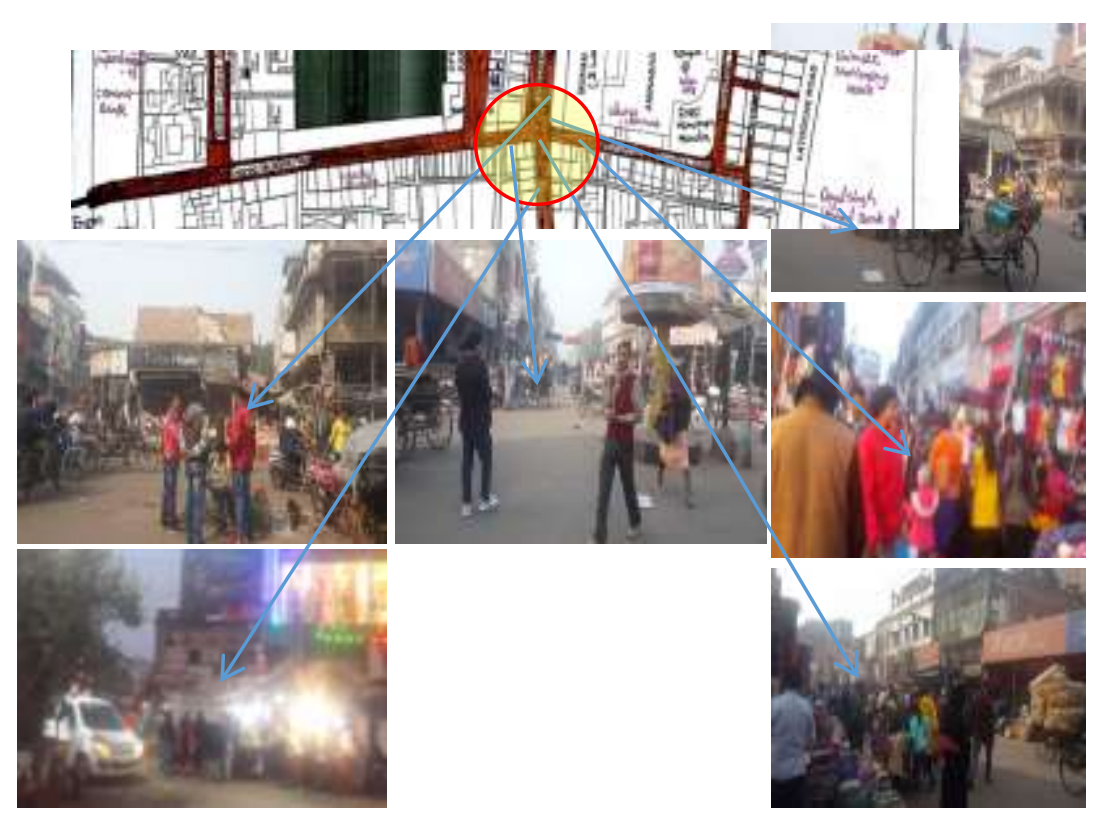

Fig 2 Aminabad Junction

Aminabad is an example of a traditional public space that is dynamic, and constantly adapts to changes for its effective use as an urban public place. The activities in the public place change several times in a day to serve specific needs and gives way for effective usage of place. However, in the present context it is apparent that the attractiveness of Aminabad as a public space has eroded.

Vehicles dominate the public space, pedestrians are given the least importance, noise and air pollution levels are at their highest, parking occupies the space meant for people, unorganized gatherings add to levels of chaos in the area. Moreover, heritage resources are in a state of neglect, infrastructural deficits are leading to unhygienic conditions of living, cultural aspects are given less importance and the space is less accessible for vulnerable populations.

Considering these conditions, the main aspects of Aminabad that need to be improved in order to reimagine Aminabad are as follows:

- Mobility aspects;

- Public place and quality of life; and

- Conservation of heritage.

Analysis of the existing situation and the discussion of future strategies to be adopted to address each of these aspects, were deliberated upon during the workshop. The following chapters explain these aspects in detail.

Despite all the challenges discussed here, Aminabad has not lost its importance as a center of the city and is large numbers of locals and tourists continue to visit it. 


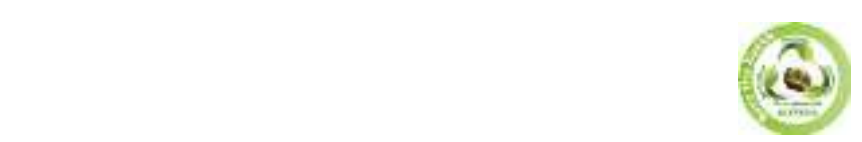

SJIF Impact Factor: 7.001| ISI I.F.Value:1.241| Journal DOI: 10.36713/epra2016

ISSN: 2455-7838(Online)

EPRA International Journal of Research and Development (IJRD)

Volume: 5 | Issue: 8 | August 2020

- Peer Reviewed Journal

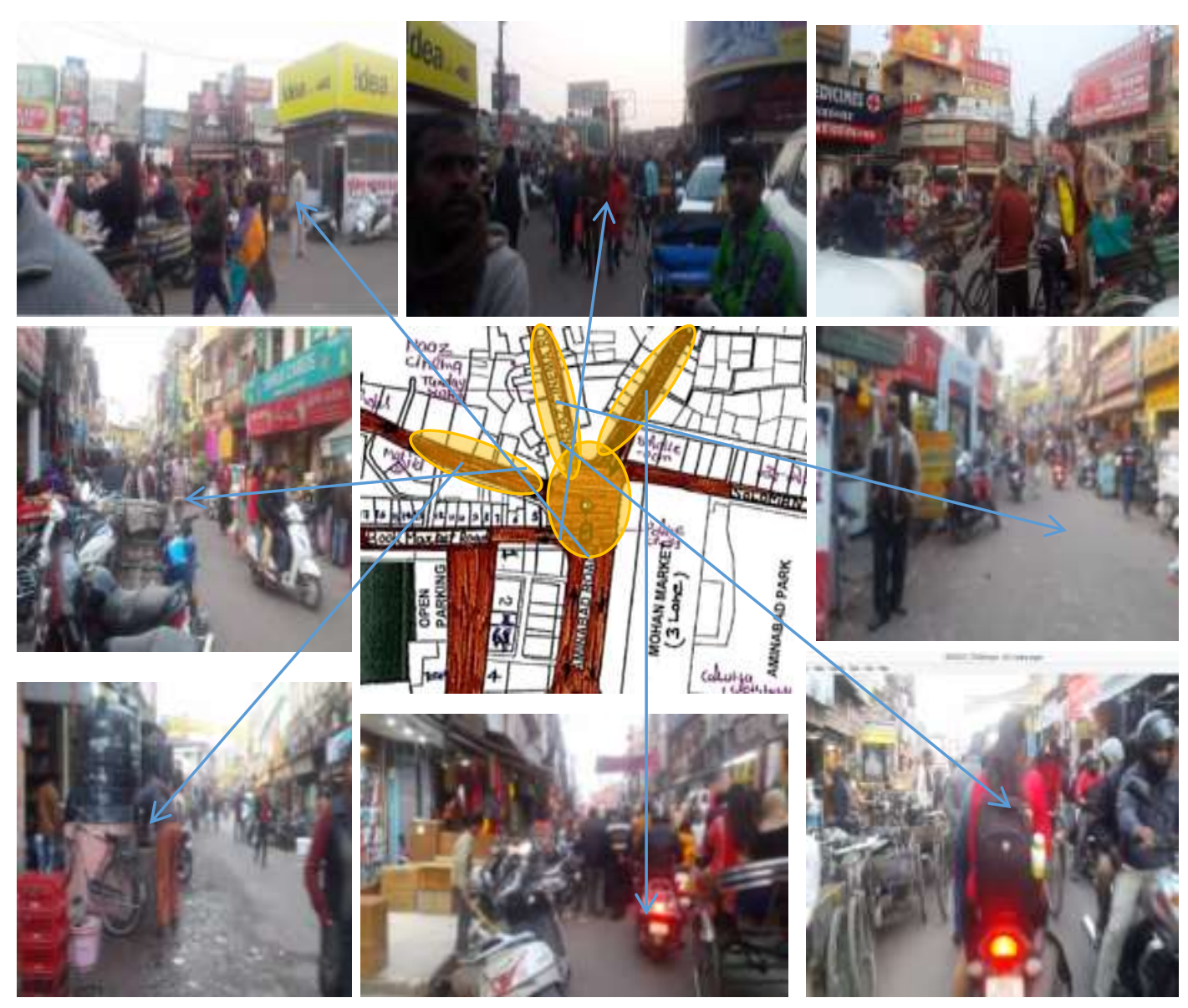

Fig 3 Existing situation of Aminabad junction

Challenges in the public realm

- $\quad$ To ensure safety against traffic and accidents, crime and violence, unpleasant sensory experiences in Aminabad;

- To ensure comfort through opportunities to walk, sit, stay, see, talk and listen, play and perform other activities in Aminabad;

- $\quad$ To enable an enjoyable experience while accessing the many opportunities possible due to the temporal nature of activities at Aminabad. 

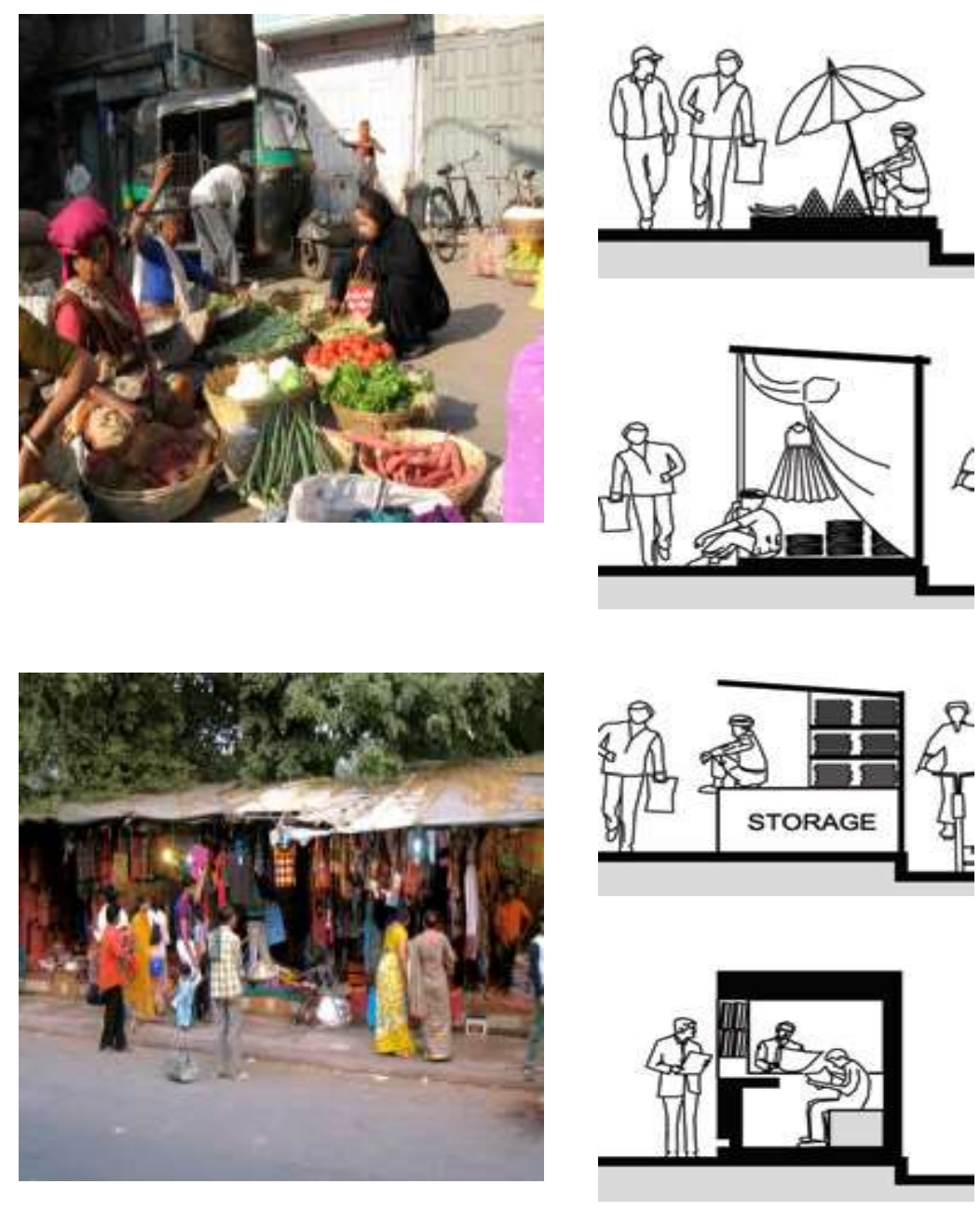

Fig 4 STREET FURNITURE AND

AMENITIES

\section{Quality of life indicators}

Quality Criteria is based on human senses of ability to see, hear, smell, feel, move and related psychological conditions The framework could be considered as a comprehensive method to analyze present condition of public spaces and to determine the aspects that needs to be improved. Based on the frame work, quality of public life in Aminabad was surveyed and presented in the workshop.

- -Reduce the impact of vehicular traffic in the Chowk and promote road safety in Aminabad and surroundings by supporting pedestrian movement and public life.

- Parking is a private activity that occupies precious public space. Parking supply should support local businesses hence long term parking should be reduced and/or shifted to an alternate location.

- Integrate Aminabad improvement along with Bhadra Chowk pedestrianization project in order to synchronize movement and sharing of parking and other facilities.

Traditional public space that is dynamic, and constantly adapts to changes for its effective use as an urban public place. The activities in the public place change several times in a day to serve specific needs and gives way for effective usage of place. However, in the present context it is apparent that the attractiveness of Aminabad as a public space has eroded. Walkability is an important concept in sustainable urban design approach. It is a measure of how friendly an area is for pedestrians. Walkability has many health, 
environmental, and economic benefits. Better walkability has shown many individual and community benefits, such as opportunities for increased social interaction, reduced crime, increased civic sense and responsibility. One of the most important benefits of walkability is the decrease of the automobile footprint from the community. Thus 'carbon emissions' can be reduced if more people choose to walk. Increased walkability has also been found to have many economic benefits both to individuals and to the public with increased efficiency of land use including accessibility, increased liveability, transportation cost savings, economic benefits from improved public health and catalyzes economic growth. In developing countries, like India, majority of the people have to walk or use public transportation. Many cities are indirectly encouraging use of public transport through introducing BRTS and/or MRTS projects thus increasing pedestrian movement. On the contrary, we observe rapid growth of vehicles on road, new proposals for flyovers or widening of roads and encourage more vehicles and the process continues, sometimes even at the cost of footpaths and pedestrian convenience and safety; thus, discouraging pedestrian movement.

\subsection{CONCLUSION}

As we know, urban growth with sprawl is completely unpleasant and unwanted and the correct solution is "intermediate cities" to integrate all of the suitable aspects in a city. As you considered, this article discusses about pedestrianisation and its benefits. In a city with large growth especially in developing countries, one of the cases that usually are neglected is pedestrianisation and attendance of citizens in urban spaces. I hope that with promoting the human's life we could be able in respecting humans' needs in cities as much as possible especially in developing countries.

\section{REFERENCES}

1. Kwan Lee Hau (2004). Pedestrianisation Schemes in Hong Kong. university of Hong Kong

2. Salingaros Nikos (2000).Theory of the Urban Web University of Texas Institute of Urban Planning publication No. 33

3. Salingaros Nikos(2004). PRINCIPLES OF URBAN STRUCTURE. Faculty of Architecture Delft University of Technology Jensen Søren Underlien. Pedestrian Safety Analyses and Safety Measures. Danish Road Directorate Division of Traffic Safety and Environment. Denmark McDonald Gregory. The Continuum of the Landscape: Promoting a Livable Network Strategy. York University A. Kushner James.
The Post-Automobile City - Legal Mechanisms to Establish the Pedestrian Friendly City. Carolina Academic Press

4. Ghobadian vahid (2003). Climatic analysis of the traditional Iranian buildings .university of Tehran press

5. Dr. Ronald G. Hughes, Dr. Ronald G. Hughes (2002). Evaluation and application of pedestrian Modelling capabilities using computer Simulation, the institute for transportation research and Education (ITRE),

6. Jen Te PAI, Jon-Jye CHENG (2007) exploring issues and strategies of developing skyway Systems: a case study of the Taipei shin-yi district. Journal of the Eastern Asia Society for Transportation Studies, Vol. 7, 2007.

7. Benard Jacob FAIA and Catrol Morphew, (1984) Skyway Typology Minneapolis, Washington DC, AIA Press.

8. Krsto Lipovac, Milan Vujanic, Bojan Maric, and Miladin Nesic (1994) Pedestrian Behavior at Signalized Pedestrian Crossings. DOI: 10.1061/ (ASCE) TE.1943-5436.0000491. (C) 2013 American Society of Civil Engineers.

9. Muhammad M. ISHAQUE (1994) pedestrian modeling in urban road networks: issues, limitations and opportunities offered by micro-simulation.

10. Ronald John Galiza and Luis Ferreira (2013) Standard Pedestrian Equivalent Factors: New Approach to Analyzing Pedestrian Flow. Journal of transportation engineering.

11. IRC 103-2012 Guidelines for Pedestrian Facilities.

12. Prabhati Bhattacharya (2004) Methodology to optimize for pedestrian delay and vehicular delay in a signal network. University of Missouri-Columbia. 